\title{
Oxygen Radicals Generated at Reflow Induce Peroxidation of Membrane Lipids in Reperfused Hearts
}

\author{
Giuseppe Ambrosio, John T. Flaherty, ${ }^{*}$ Carlo Duilio, Isabella Tritto, Giuseppe Santoro, \\ Pietro P. Elia, Mario Condorelli, and Massimo Chiariello \\ Division of Cardiology, 2nd School of Medicine, University of Naples, 80131 Naples Italy; and
}

*Division of Cardiology, Johns Hopkins Hospital, Baltimore, Maryland 21205

\begin{abstract}
To test whether generation of oxygen radicals during postischemic reperfusion might promote peroxidation of cardiac membrane lipids, four groups of Langendorff-perfused rabbit hearts were processed at the end of $(a)$ control perfusion, (b) $30 \mathrm{~min}$ of total global ischemia at $37^{\circ} \mathrm{C}$ without reperfusion, (c) $30 \mathrm{~min}$ of ischemia followed by reperfusion with standard perfusate, $(d)$ $30 \mathrm{~min}$ of ischemia followed by reperfusion with the oxygen radical scavenger human recombinant superoxide dismutase (h-SOD). The left ventricle was homogenized and tissue content of malonyldialdehyde (MDA), an end product of lipid peroxidation, was measured on the whole homogenate as well as on various subcellular fractions. Reperfusion was accompanied by a significant increase in MDA content of the whole homogenate and of the fraction enriched in mitochondria and lysosomes. This phenomenon was not observed in hearts subjected to ischemia but not reperfused, and was similarly absent in those hearts which received h-SOD at reflow. Reperfused hearts also had significantly greater levels of conjugated dienes (another marker of lipid peroxidation) in the mitochondrial-lysosomal fraction. Again, this phenomenon did not occur in ischemic hearts or in reperfused hearts treated with h-SOD. Unlike the effect on tissue MDA and conjugated dienes, reperfusion did not significantly stimulate release of MDA in the cardiac effluent. Treatment with h-SOD was also associated with significant improvement in the recovery of cardiac function. In conclusion, these data directly demonstrate that postischemic reperfusion results in enhanced lipid peroxidation of cardiac membranes, which can be blocked by h-SOD, and therefore is most likely secondary to oxygen radical generation at reflow. (J. Clin. Invest. 1991. 87:2056-2066.) Key words: lipid peroxidation • myocardial ischemia • oxygen radicals • reperfusion injury • superoxide dismutase
\end{abstract}

\section{Introduction}

It has been suggested that oxygen radical-mediated tissue damage may reduce the beneficial effects of reperfusing ischemic myocardium (1). This hypothesis is supported by the observa-

This study was presented in part at the 61 st Scientific Meeting of the American Heart Association, Washington, DC, November 1988.

Address reprint requests to Dr. Ambrosio, Cattedra di Cardiologia, II Facoltà di Medicina, Via S. Pansini 5, 80131 Naples, Italy.

Received for publication 12 April 1990 and in revised form 28 January 1991.

J. Clin. Invest.

(c) The American Society for Clinical Investigation, Inc. 0021-9738/91/06/2056/11 \$2.00

Volume 87, June 1991, 2056-2066 tion that significant quantities of oxygen radicals are generated at the time of postischemic reflow (2-5) and by studies showing that administration of oxygen radical scavengers may result in greater recovery of contractility (6-9) and smaller infarct size $(10,11)$, as compared to reperfusion alone. However, the mechanisms involved in oxygen radical-mediated reperfusion injury are still poorly understood.

Lipid peroxidation has been proposed to be a major mechanism of oxygen free radical toxicity. Unsaturated fatty acids are particularly susceptible to oxygen radical attack, owing to the presence of double bonds which can undergo peroxidation through a chain of oxidative reactions (12). Studies performed in vitro suggest that exposure to oxygen radicals results in peroxidation of membrane lipids, which is accompanied by damage to cellular organelles and to membrane-bound enzymes (13-16). If a similar mechanism were also operative in vivo, increased levels of lipid peroxidation products should be found in reperfused hearts as a consequence of oxygen radical formation at reflow. The absence of a link between oxygen radicals and lipid peroxidation would cast serious doubts over the importance of these mechanisms in the pathogenesis of reperfusion injury. In contrast, demonstration of such a relationship would provide additional support to the hypothesis that the surge of oxygen radicals observed in reperfused hearts may exert major biological effects. This is a potentially important issue, since there is still considerable controversy over the role played by oxygen radicals in reperfusion injury $(17,18)$.

Previous studies have sought to address this issue, without reaching a definitive conclusion. In some studies, hearts were subjected to ischemia, but not reperfused (19-21). Other experiments performed in the model of the "oxygen paradox" also left the question open, since reoxygenation after a period of hypoxic perfusion resulted in increased cardiac levels of malonyldialdehyde (MDA), ${ }^{1}$ an end-product of lipid peroxidation, in one study $(22)$, but not in two others $(23,24)$. However, it is unclear to what extent oxygen paradox is representative of the injury which may ensue after reperfusion of previously ischemic myocardium. Romaschin et al. (25) were the first to clearly demonstrate increased lipid peroxidation in hearts reperfused after ischemia. They documented that tissue levels of conjugated dienes, another marker of lipid peroxidation, were unchanged in dog hearts subjected to ischemia alone, but markedly rose after reperfusion. This finding provided strong evidence for a link between reperfusion and lipid peroxidation. However, the role of oxygen radicals in this phenomenon was not investigated in that study, and thus it could not be excluded that mechanisms other than oxygen radicals (e.g., increased prostanoid synthesis $[12,26])$ were responsible for the in-

1. Abbreviations used in this paper: $\mathrm{h}-\mathrm{SOD}$, human recombinant superoxide dismutase; MDA, malonyldialdehyde; TBA, thiobarbituric acid. 
creased lipid peroxidation seen upon reperfusion. This concern is strengthened by recent observations by Koller and Bergmann (27). In a different model of reperfusion after a period of flow reduction, they observed an increase in cardiac MDA content, which was not prevented by administration of oxygen radical scavengers. Thus, it is still unclear whether oxygen radicals generated during reperfusion can induce cardiac lipid peroxidation. Furthermore, with the exception of a very recent report (28), in previous studies conjugated dienes or MDA were measured only in the whole homogenate of cardiac tissue. Therefore, there is little experimental evidence to establish whether any increase in these products is attributable to lipid peroxides present in the cytosol (which may not necessarily derive from oxygen radical attack), or whether these products are actually associated with membranes from one or more subcellular fraction(s), which might imply damage by oxygen radicals.

In the present study we sought to directly assess whether lipids of cardiac membranes undergo peroxidation during postischemic reperfusion, as a specific consequence of oxygen free radical generation beginning at reflow. The experiments were -performed in a previously characterized animal model which develops oxygen radical-mediated reperfusion injury (i.e., isolated perfused rabbit hearts subjected to $30 \mathrm{~min}$ of total global ischemia followed by reperfusion). Lipid peroxidation products were measured in subcellular fractions from reperfused hearts receiving or not receiving the specific oxygen radical scavenger superoxide dismutase (SOD) at the time of reflow, as well as from hearts subjected to ischemia but not reperfusion.

\section{Methods}

\section{Isolated heart preparation}

Female New Zealand White rabbits (1.7-2.2 kg) were heparinized and anesthetized with i.p. thiopental. The hearts were excised and perfused at $37^{\circ} \mathrm{C}$ at a constant pressure of $80 \mathrm{~mm} \mathrm{Hg}$. The buffer contained 117 $\mathrm{mM} \mathrm{NaCl}, 6.0 \mathrm{mM} \mathrm{KCl}, 3.0 \mathrm{mM} \mathrm{CaCl}, 1.0 \mathrm{mM} \mathrm{MgSO}{ }_{4}, 0.5 \mathrm{mM}$ EDTA, $16.7 \mathrm{mM}$ glucose, and $24 \mathrm{mM} \mathrm{NaHCO}$, with pH 7.4. The perfusate was bubbled with a gas mixture of $95 \% \mathrm{O}_{2}$ and $5 \% \mathrm{CO}_{2}$ and not recirculated. Right ventricular pacing at 180 beats/min was achieved by means of a stimulation catheter connected to a stimulator (Harvard Apparatus Co., Inc., S. Natick, MA). To assess contractile function, a latex balloon was inserted into the left ventricular cavity through the mitral orifice, and connected to a pressure transducer (model P23dB, Statham-Gould, Cleveland, $\mathrm{OH}$ ). The balloon was initially inflated with saline to produce an end-diastolic pressure of 10 $\mathrm{mm} \mathrm{Hg}$, which is on the plateau of the Starling curve for this preparation. All subsequent measurements of developed pressure, calculated as the difference between peak systolic and end-diastolic pressure, were made at this same end-diastolic volume. Left ventricular pressure was recorded on a recorder (model 2400 S, Statham-Gould). The venae cavae were ligated, and the pulmonary artery was cannulated to collect the effluent from the coronary sinus via the right atrium and ventricle.

\section{Experimental protocol}

After a 20-min equilibration period, baseline parameters were recorded. Total global ischemia was then induced by cross-clamping the perfusion line. Hearts were maintained at $37^{\circ} \mathrm{C}$ throughout ischemia by immersion in warm perfusate. During ischemia the intraventricular balloon was deflated, and the pacer turned off.

Eight control hearts were not made ischemic, but were processed after continuous perfusion for $45 \mathrm{~min}$ after the 20 -min period of equilibration. Eight hearts were processed at the end of the ischemic period, without reperfusion. Sixteen hearts were reperfused. At the time of reflow, untreated control hearts $(n=8)$ received a bolus of standard perfusate ( $10 \mathrm{ml}$ delivered over $30 \mathrm{~s}$ ), followed by $45 \mathrm{~min}$ of reperfusion. Treated hearts $(n=8)$ received a bolus of $60,000 \mathrm{IU}$ of the superoxide radical scavenger recombinant human SOD (h-SOD, specific activity $3,200 \mathrm{IU} / \mathrm{mg}$ ), followed by a continuous infusion of $2,600 \mathrm{IU} /$ min during the first 15 min of reflow. The $\mathrm{Cu}-\mathrm{Zn}$ form of h-SOD was expressed in Escherichia coli and supplied courtesy of Bio-Technology General Corp., New York, NY. After the initial 15 min of reperfusion, hearts receiving h-SOD were switched to standard perfusate for the remaining $30 \mathrm{~min}$ of the 45 -min reperfusion period. Previous studies in this same animal model have shown that the administration of $h-S O D$ at reflow essentially blocks the surge of oxygen radical generation seen in untreated hearts following reperfusion $(3,29)$. Pacing was reinstituted at the onset of reflow, and after $15 \mathrm{~min}$ of reperfusion the balloon was reinflated. Isovolumic developed pressure was measured after 15 , 30 , and $45 \mathrm{~min}$ of reflow.

MDA concentration in the coronary effluent was measured in samples of coronary venous effluent collected over 15-s intervals throughout the first 4 min of reflow, and then on 15-s aliquots collected at 5, 10, 15,30 , and $45 \mathrm{~min}$ of reperfusion. At the end of the experiment, all hearts were removed from the perfusion apparatus, weighed, and processed for biochemical assay.

\section{Tissue homogenization}

Both atria and the right ventricle were removed, and the left ventricle was homogenized in $9 \mathrm{vol}$ of $1.15 \% \mathrm{KCl}$ solution (30). To prevent auto-oxidation of the samples, homogenization was carried out at $4^{\circ} \mathrm{C}$ in nitrogen-equilibrated solutions, in the presence of $10 \mu \mathrm{M}$ deferoxamine, $0.04 \%$ butylated hydroxytoluene, and $2 \%$ ethanol $(30,31)$. The homogenate was initially centrifuged at $1,000 \mathrm{~g}$ for $10 \mathrm{~min}$ at $4^{\circ} \mathrm{C}$ to remove nuclei and tissue debris. One aliquot of the supernatant (referred to as "whole homogenate") was stored for MDA assay, and the remainder was divided in two tubes and centrifuged at $30,000 \mathrm{~g}$ for 30 min at $4^{\circ} \mathrm{C}$. Of the two pellets, one was resuspended in $4 \mathrm{ml}$ of the homogenization buffer for MDA assay, and the other was used for conjugated diene and lipid hydroperoxide assays (see below). The supernatants were combined and stored at $-70^{\circ} \mathrm{C}$. After $2-3 \mathrm{~d}$, this supernatant fraction was thawed and further centrifuged at $100,000 \mathrm{~g}$ for $60 \mathrm{~min}$ at $4^{\circ} \mathrm{C}$, and the sediment was resuspended in $2 \mathrm{ml}$ of homogenization buffer. Previous studies in intact hearts (32), as well as in isolated myocytes (33), showed that the $30,000-g$ pellet contains mostly mitochondria and heavy lysosomes, whereas the microsomal fraction is recovered in the $100,000-g$ sediment; the final supernatant contains soluble cytosolic material. This distribution of subcellular organelles was confirmed in the present study by assaying for specific marker enzymes (see below)

The whole homogenate, as well as the various subcellular fractions, were assayed for MDA content. MDA content was also measured in the effluent from the coronary sinus. Conjugated diene and lipid hydroperoxide levels were measured after lipid extraction of the mitochondrial-lysosomal fraction, since preliminary experiments had shown that lipid peroxidation products were particularly abundant in this fraction.

\section{Biochemical measurements}

Tissue MDA assay. MDA content was measured by a modified thiobarbituric acid (TBA) method $(34,35)$. Briefly, $0.6 \mathrm{ml}$ of sodium dodecyl sulfate $(8.1 \%)$ were added to $0.4 \mathrm{ml}$ of sample. To minimize artifactual production of MDA from breakdown of lipid peroxides during the assay, deferoxamine $(4 \mu \mathrm{M})$, butylated hydroxytoluene $(0.16 \%)$ and ethanol $(8 \%)$ were present in the sample $(30,31)$. The sample was then treated with $3 \mathrm{ml}$ of $20 \%$ acetic acid and $3 \mathrm{ml}$ of $0.8 \%$ TBA, and incubated for $90 \mathrm{~min}$ at $95^{\circ} \mathrm{C}$ in an oil bath. After cooling, the samples were extracted with $2 \mathrm{ml}$ of butanol/pyridine (15:1), and the absorbance read at $532 \mathrm{~nm}$. Calibration curves were prepared daily, using a standard of malonyldialdehyde tetraethylacetal (which hydrolyses to yield MDA). The assay was linear across the $0.2-2.0 \mathrm{nmol} / \mathrm{sample}$ range. In preliminary experiments, we performed the assay on left ven- 
tricular homogenates to which variable amounts of malonyldialdehyde standard were added. We found $91 \pm 4 \%$ recovery of the MDA added, over a broad range of concentrations $(0.2-2.5 \mathrm{nmol} / \mathrm{sample})$.

Conjugated diene assay. To estimate the conjugated diene content of the mitochondrial-lysosomal fraction, lipids were extracted from the $30,000-g$ pellet by the method of Folch et al. (36). The lipid-containing phase was removed and dried under a stream of oxygen-free nitrogen gas at room temperature. The dried samples were then resuspended in hexane (spectroscopic grade, from Aldrich Chemical Co. Ltd., Gillingham-Dorset, UK). Quantitation of conjugated diene content in each sample was obtained by measuring the absorbance at $233 \mathrm{~nm}$ in a double-beam spectrophotometer (model UV-Kon, Kontron Analytical, Everett, MA), using a molar extinction coefficient of 28,000 (37). Since the specific absorption peak of conjugated dienes at $233 \mathrm{~nm}$ can appear as a shoulder on the much higher peak of unsaturated lipids (which give a broad peak around $200 \mathrm{~nm}$ ), the samples were read against a reference prepared by pooling aliquots of the lipid extract from the eight normally-perfused hearts. Care was taken to bring the lipid content of the reference sample to the value of each sample to be tested. By this procedure, the contribution of unsaturated lipids to the absorbance could be eliminated by differential spectroscopy. The results are expressed as delta nanomoles $(\Delta \mathrm{nmol})$ of conjugated dienes in experimental hearts over the level in normal hearts.

Lipid hydroperoxide assay. Lipid hydroperoxide content was measured on the lipid extract of the mitochondrial-lysosomal fraction by iodometric titration, as described by Aust (38). Calibration curves were prepared daily, using cumene hydroperoxide as a standard.

Marker enzymes. The relative distribution of various organelles was assessed on the two fractions obtained after the 30,000-g centrifugation. Spectrophotometric assays were employed to measure the activity of cytochrome-c-oxidase, a marker of mitochondrial membranes (39), $\mathrm{N}$-acetyl-glucosaminidase, a marker of lysosomes (40), and rotenoneinsensitive NADH cytochrome-c-reductase, a marker of microsomes (41).

Protein assay. Protein content of the various fractions was measured by the method of Lowry et al. (42), using bovine serum albumin as a standard.

MDA assay on the coronary venous effluent. MDA content of the coronary sinus effluent was measured by a modification of the TBA method of Buege and Aust (43). Briefly, $1.5 \mathrm{ml}$ of perfusate were added to $0.5 \mathrm{ml}$ of a solution containing $30 \%$ trichloroacetic acid, $0.75 \%$ TBA, and $0.5 \mathrm{~N} \mathrm{HCl}$, and boiled for $20 \mathrm{~min}$. After cooling, the samples were centrifuged and the supernatant read at $532 \mathrm{~nm}$. Calibration curves were prepared daily using MDA tetraethylacetal as a standard.

\section{Chemicals}

High purity grade reagents from Carlo Erba S.p.A., Milan, Italy were dissolved in double distilled water to prepare the perfusate. All other chemicals were purchased from Sigma Chemical Co., St. Louis, MO.

\section{Statistical analysis}

Data are presented as mean \pm standard error of the mean. Overall statistical significance for differences in tissue MDA and lipid hydroperoxide content across the various groups was tested by analysis of variance. Comparisons between groups were then made by Bonferroni corrected $t$ test. In the case of conjugated dienes, statistical significance was tested by nonparametric Kruskaal-Wallis $U$ test. In the two groups of reperfused hearts, the time course of MDA release in the coronary sinus, and that of recovery of functional parameters, were compared by repeated measures analysis of variance (ANOVA). Comparisons at individual time points were made, when appropriate, by unpaired $t$ test.

\section{Results}

Tissue MDA levels

Whole-heart homogenate. MDA content in normally perfused control hearts averaged $1.02 \pm 0.10 \mathrm{nmol} / \mathrm{mg}$ of protein. This parameter was slightly but not significantly greater than controls in the hearts processed after $30 \mathrm{~min}$ of ischemia, whereas it was significantly higher in reperfused hearts $(1.48 \pm 0.10 \mathrm{nmol} /$ mg of protein; $P<0.05$ vs. controls; Fig. 1). This increase in lipid peroxidation was prevented by treatment with h-SOD at the time of reperfusion $(P<0.05$ vs. untreated reperfused hearts; Fig. 1).

Mitochondrial-lysosomal fraction. As was the case for the whole-heart homogenate, MDA content in the mitochondriallysosomal fraction obtained from hearts subjected to ischemia alone was not different from controls $(1.18 \pm 0.16$ vs. $0.99 \pm 0.09$ $\mathrm{nmol} / \mathrm{mg}$ of protein, respectively; Fig. 2, upper panel). However, MDA content was almost doubled in the mitochondriallysosomal fraction obtained from reperfused hearts $(1.83 \pm 0.32$ $\mathrm{nmol} / \mathrm{mg}$ of protein; $P<0.05$ vs. controls; Fig. 2, upper panel). This reperfusion-induced increase in MDA content (lipid peroxidation) was not observed in h-SOD-treated hearts $(1.03 \pm 0.17 \mathrm{nmol} / \mathrm{mg}$ protein; $P<0.05$ vs. untreated reperfused hearts; Fig. 2, upper panel).

Microsomal fraction. Hearts subjected to ischemia alone showed a significantly greater MDA content in the microsomal fraction than normally perfused control hearts $(P<0.05$; Fig. 2 , middle panel). This increase in MDA content was not observed in untreated reperfused hearts (Fig. 2, middle panel). MDA levels in the microsomal fraction from h-SOD-treated reperfused hearts were lower than untreated reperfused hearts. However, this difference did not reach statistical significance (Fig. 2, middle panel).

Cytosolic fraction. MDA content in the soluble cytosol averaged $0.97 \pm 0.29 \mathrm{nmol} / \mathrm{mg}$ of protein in normal hearts. No significant differences were observed among the four experimental groups (Fig. 2, lower panel).

\section{Tissue-conjugated diene content}

Fig. 3 shows typical differential absorbance spectra obtained from each of the three experimental groups subjected to ischemia. A peak centered at $233 \mathrm{~nm}$, representing the signal due to conjugated dienes, can be seen in all hearts. However, the intensity of this peak was dramatically different in the various groups. In the mitochondrial-lysosomal fraction of hearts subjected to ischemia alone, the peak due to conjugated dienes was barely detectable. In contrast, reperfusion was associated with a marked increase in conjugated diene content $(P<0.05$ vs.

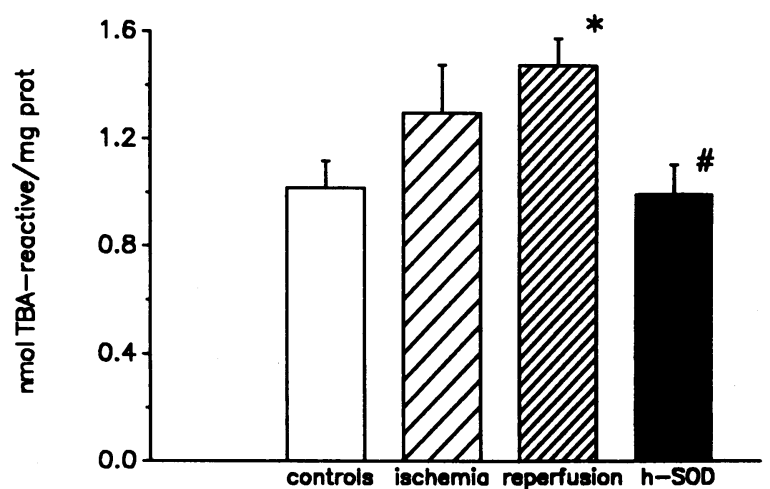

Figure 1. MDA content (expressed as nanomoles of thiobarbituratereactive material per milligram of protein) in the whole homogenate of the left ventricle from the various experimental groups. ${ }^{*} P<0.05$ vs. control hearts. " $P<0.05$ vs. untreated reperfused hearts. 


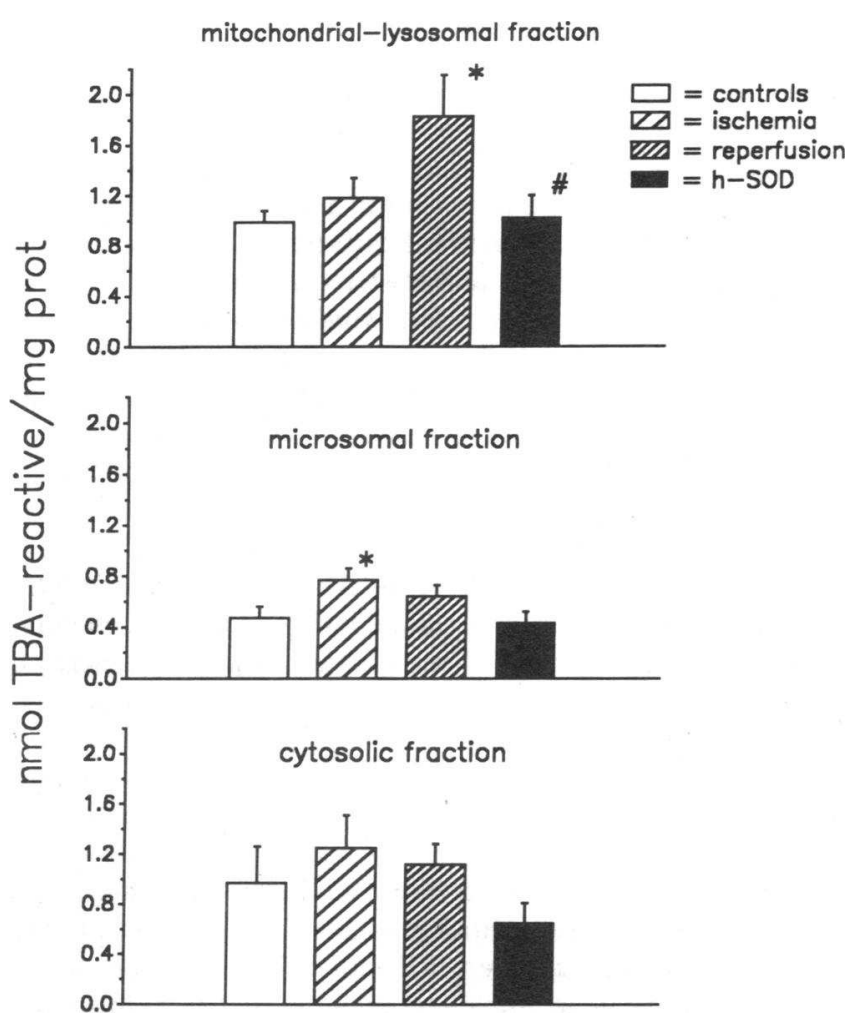

Figure 2. MDA content (expressed as nanomoles of thiobarbituratereactive material per milligram of protein) in different subcellular fractions from the various experimental groups. ${ }^{*} P<0.05$ vs. control hearts. ${ }^{~} P<0.05$ vs. untreated reperfused hearts.

ischemia alone; Figs. 3 and 4). Treatment with h-SOD at the time of reflow largely prevented this phenomenon. Conjugated diene content of the mitochondrial-lysosomal fraction in $\mathrm{h}$ SOD-treated hearts was similar to that of hearts subjected to ischemia alone (Figs. 3 and $4 ; P<0.05$ vs. untreated reperfused hearts).

\section{Tissue lipid hydroperoxide content}

Lipid hydroperoxide content in the mitochondrial-lysosomal fraction from normally perfused control hearts averaged $5.52 \pm 2.06 \mathrm{nmol} / \mathrm{mg}$ of protein. No differences in this index of lipid peroxidation were observed among the four experimental groups (Fig. 5).

\section{Marker enzymes}

The distribution of marker enzymes in the two fractions obtained after the 30,000- $g$ centrifugation was assessed in 12 hearts (three from each group) (Table I). In control hearts, the activity of the mitochondrial marker cytochrome-c-oxidase was $>20$-fold enriched in the sediment, as compared to the supernatant (which was subsequently recentrifuged to isolate the microsomal fraction from the cytosol). In the remaining three groups, cytochrome- $c$-oxidase content in the sediment was also similar to that of control hearts, although the activity in the supernatant was slightly higher in those hearts. This finding confirms that mitochondria were mostly confined to the $30,000-g$ sediment.

Unlike the mitochondrial marker enzyme, the marker enzymes for lysosomes and microsomes were present in the sediment as well as in the supernatant, indicating some contamination of the mitochondrial fraction by lysosomes and microsomal membranes. A greater activity of $N$-acetyl-glucosaminidase was found in the supernatant fraction of homogenates from postischemic hearts, as compared to controls. This might suggest that ischemia altered the sedimentation properties of lysosomes. Alternatively, it might also reflect increased fragility of the lysosomes as a consequence of the ischemic insult, with partial release of enzymes in the cytosol during sample processing.

\section{$M D A$ release in the coronary effluent}

Little basal release of thiobarbiturate-reactive material was observed in the two groups of hearts which were to be subjected to ischemia and reperfusion. After reflow, untreated hearts showed a small increase in the release of MDA in the coronary

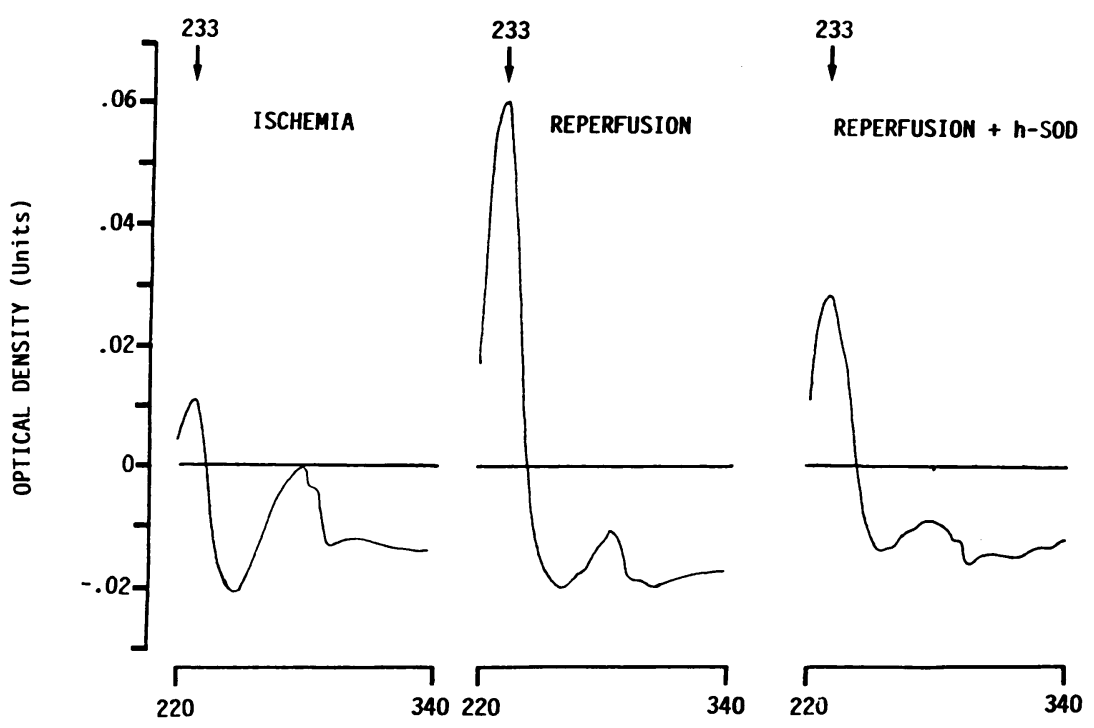

WAVELENGTH $(\mathrm{nm})$
Figure 3. Typical differential absorbance spectra of the lipid extract from the mitochondrial-lysosomal fraction from a heart subjected to ischemia but not reperfused (left panel), a reperfused heart (middle panel), and a heart treated with h-SOD at the time of reflow (right panel). The spectra represent the difference in absorbance of each sample with respect to a pool of normal hearts, at various wavelengths. The horizontal line marks the identity line. Absorbance is plotted as optical density units. Notice the different magnitude of the peak at $233 \mathrm{~nm}$ in the three hearts. 


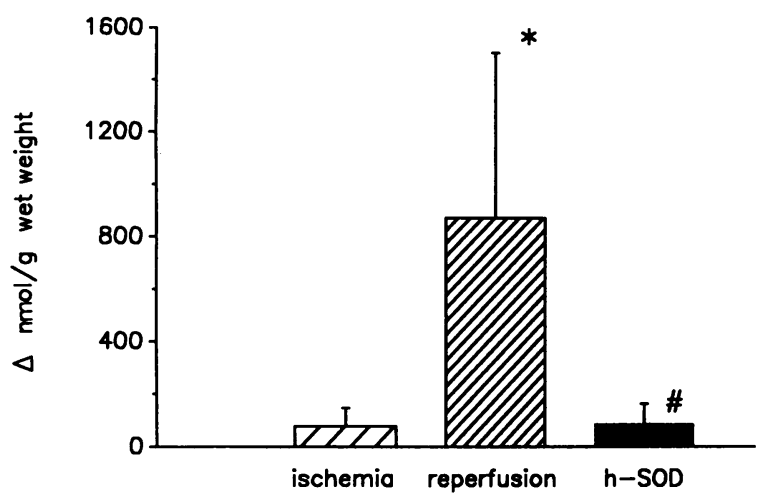

Figure 4. Conjugated dienes content of the lipid extract from the mitochondrial-lysosomal fraction of the three groups of hearts subjected to ischemia, with or without reperfusion. Data are expressed as the delta (in nanomoles per gram wet weight) over a pool of normal hearts. ${ }^{*} P<0.05$ vs. control hearts. $P<0.05$ vs. untreated reperfused hearts by nonparametric Kruskaal-Wallis $U$ test.

effluent, which persisted throughout reperfusion at concentrations just above baseline (Fig. 6). In h-SOD hearts MDA release tended to be initially greater, showing a transient overshoot during the first minute of reflow, followed by a decline, and by a second increase between 4 and 10 min of reperfusion (Fig. 6). However, these differences did not achieve statistical significance. Furthermore, during the remainder of the study MDA release in the h-SOD-treated group was similar to or lower than that observed in untreated reperfused hearts (Fig. 6). Consequently, total cumulative release of MDA was identical in the two groups $(24.8 \pm 7.2 \mathrm{nmol} / \mathrm{g}$ wet weight in untreated hearts vs. $24.4 \pm 8.1 \mathrm{nmol} / \mathrm{g}$ wet weight in h-SOD-treated hearts) by the end of the 45-min reperfusion period.

\section{Functional parameters}

Developed pressure. Developed pressure before ischemia was similar in both groups $(106.1 \pm 5.8 \mathrm{~mm} \mathrm{Hg}$ in untreated hearts vs. $104.6 \pm 6.1 \mathrm{~mm} \mathrm{Hg}$ in the group to be treated with $\mathrm{h}-\mathrm{SOD}$ ). In untreated hearts reperfused after $30 \mathrm{~min}$ of ischemia recovery of developed pressure was markedly impaired, averaging $47.7 \pm 6.8 \%$ of baseline at the end of $45 \mathrm{~min}$ of reflow (Table II). Recovery of developed pressure was significantly greater in hearts receiving $\mathrm{h}-\mathrm{SOD}$ at the time of reflow $(60.6 \pm 3.1 \%$ of preischemia baseline; $P<0.05$ vs. untreated reperfused hearts; Table II), consistent with the notion that oxygen radical generation can affect recovery of contractility in reperfused hearts (6-9, 29).

End-diastolic pressure. Oxygen radical generation also largely affected recovery of end-diastolic pressure. End-diastolic pressure in untreated reperfused hearts averaged $33.3 \pm 7.8 \mathrm{~mm} \mathrm{Hg}$ at the end of the reperfusion period, a greater than threefold increase over preischemic values, whereas it was significantly lower in the group treated with h-SOD at reflow (18.9 $\pm 2.4 \mathrm{~mm} \mathrm{Hg} ; P<0.05$; Table II).

Coronary flow. Baseline values of coronary flow were similar in both groups $(7.3 \pm 0.8 \mathrm{ml} / \mathrm{min}$ per $\mathrm{g}$ wet weight in the control group vs. $7.3 \pm 0.5$ in the group to be treated with $h$ SOD). Hearts treated with h-SOD also tended to have better recovery of coronary flow than untreated hearts during reperfusion. However, this tendency did not reach statistical significance (Table II).

\section{Discussion}

In the present study reperfusion of rabbit hearts after a period of ischemia resulted in increased membrane lipid peroxidation, as compared to control hearts as well as to hearts subjected to ischemia alone. Furthermore, the increase seen in untreated reperfused hearts was not seen in hearts treated with the oxygen radical scavenger, h-SOD, administered at the time of reflow. These data demonstrate that following postischemic reperfusion myocardial membrane lipids may undergo peroxidation and, since this effect was blocked by h-SOD, as a specific consequence of oxygen radical generation.

Previous studies have shown that postischemic reperfusion is associated with increased cardiac accumulation of lipid peroxidation products $(25,27,28)$. Romaschin et al. $(25,28)$ have documented increased myocardial levels of conjugated dienes induced by reperfusion in a canine model of global ischemia. Koller and Bergmann (27) demonstrated a significant increase in MDA content in isolated rabbit hearts reperfused after a period of low-flow ischemia. However, the role of oxygen radicals in this phenomenon remained to be clarified. Romaschin et al. $(25,28)$ did not attempt to influence lipid peroxidation through an intervention aimed at reducing oxygen radicals concentrations. On the other hand, Koller and Bergmann (27) were not able to prevent lipid peroxidation by administration of oxygen radical scavengers. This finding might negate a role of oxygen radicals in this phenomenon. However, this latter study differs from ours in some important aspects, which might explain the divergent results obtained with regard to the effects of oxygen radical scavengers. Electron paramagnetic resonance studies have shown that oxygen radical concentration in crystalloid perfused rabbit hearts is maximal during the initial 30 sec of reflow $(2,3,29,44)$. During this crucial phase, the dose of SOD administered by Koller and Bergmann was $1 / 40$ th of that employed in this, as well as in previous studies $(9,29)$. Since there were no measurements of oxygen radical concentration, nor there was any other evidence of reduction of reperfusion injury, it might be argued that the dose of SOD employed by Koller and Bergmann was insufficient to effectively scavenge superoxide radicals. In addition, that study utilized a model of low-flow ischemia, as opposed to our study in which total ischemia was induced by completely abolishing coronary flow. There is increasing evidence to indicate that in the heart the severity of ischemia may dictate the magnitude of subsequent

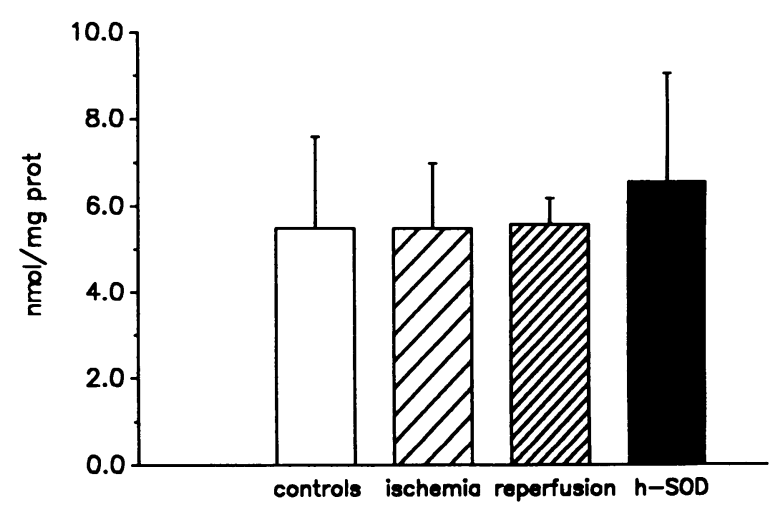

Figure 5. Lipid hydroperoxide content of the mitochondrial-lysosomal fraction of the various experimental groups. 
Table I. Distribution of Marker Enzymes after Centrifugation at $30,000 \mathrm{~g}$

\begin{tabular}{lcccc}
\hline & Controls & Ischemia & Reperfusion & h-SOD \\
\hline & Cytochrome-c-oxidase (U/mg protein) \\
Sediment & $0.73 \pm 0.18$ & $0.62 \pm 0.16$ & $0.71 \pm 0.08$ & $0.74 \pm 0.17$ \\
Supernatant & $0.03 \pm 0.04$ & $0.09 \pm 0.08$ & $0.13 \pm 0.15$ & $0.10 \pm 0.11$
\end{tabular}

$\mathrm{N}$-acetyl-glucosaminidase ( $\mathrm{mU} / \mathrm{mg}$ protein)

$\begin{array}{lrrlr}\text { Sediment } & 11 \pm 8 & 12 \pm 6 & 10 \pm 2 & 8 \pm 2 \\ \text { Supernatant } & 1 \pm 2 & 16 \pm 9 & 25 \pm 10 & 23 \pm 10\end{array}$

Cytochrome-c-reductase ( $\mathrm{U} / \mathrm{mg}$ protein)

$\begin{array}{lllll}\text { Sediment } & 0.19 \pm 0.07 & 0.24 \pm 0.10 & 0.26 \pm 0.17 & 0.37 \pm 0.14 \\ \text { Supernatant } & 0.27 \pm 0.10 & 0.32 \pm 0.14 & 0.33 \pm 0.12 & 0.40 \pm 0.09\end{array}$

"Sediment" refer to the subcellular fraction identifed in the text as "mitochondrial-lysosomal fraction." The supernatant was subsequently centrifuged at $100,000 \mathrm{~g}$ to isolate microsomal membranes from soluble cytosolic proteins.

oxygen radical-mediated reperfusion injury $(4,11,44-47)$. Better tissue preservation during ischemia, and/or reduced accumulation of substrates for oxygen radical formation upon reflow, might account for reduced susceptibility to oxygen radical damage in hearts subjected to relatively milder ischemia. This latter hypothesis is directly supported by recent experiments showing that oxygen radicals concentrations at reflow correlates with the severity of collateral flow deprivation during regional myocardial ischemia in dogs (47), and with the duration of global ischemia in isolated hearts $(4,44)$. Finally, data in kidney demonstrate that, although reflow after total ischemia is associated with oxygen radical-mediated lipid peroxidation (48), reperfusion after a period of reduced perfusion may not induce these effects (49). Thus, it is possible that the low-flow ischemia protocol employed by Koller and Bergmann did not result in oxygen radical-induced lipid peroxidation. The increase in MDA seen in that study might thus be secondary to other mechanisms (e.g., enhanced prostanoid synthesis [12, 26]), which might also be activated by postischemic reperfusion.

The present study employed an experimental model which has been previously characterized with respect to the time course of oxygen radical generation after reperfusion $(29,44)$, as well as to the beneficial effects of several anti-free radical interventions administered at the time of reflow $(3,9,29,50)$. Subcellular fractionation suggests that myocardial lipid peroxidation was largely localized to the membranes of certain organelles. The administration of the specific radical scavenger $h$ SOD beginning at the time of reflow rules out any possibility that beneficial effects might have occurred during ischemia. Thus, our data provide direct evidence that oxygen radicals generated upon postischemic reflow induce peroxidation of myocardial membrane lipids. h-SOD administration at the time of reperfusion prevented this membrane lipid peroxidation, and as was also shown in previous studies $(9,29,45)$, h-SOD treatment at reflow also resulted in significant improvement of left ventricular contractile recovery and high-energy phosphate metabolism, consistent with reduction of reperfusion injury in treated hearts.

Lipid peroxidation is a complex phenomenon, which proceeds through several steps, the exact sequence of which has only been partially elucidated (12) (Fig. 7). The reaction sequence is thought to be initiated by abstraction of a hydrogen atom from a molecule of unsaturated fatty acid, resulting in the formation of a relatively stable alkyl free radical $\left(R^{\circ}\right)$, which, in the presence of $\mathrm{O}_{2}$, triggers a chain of auto-oxidative reac-

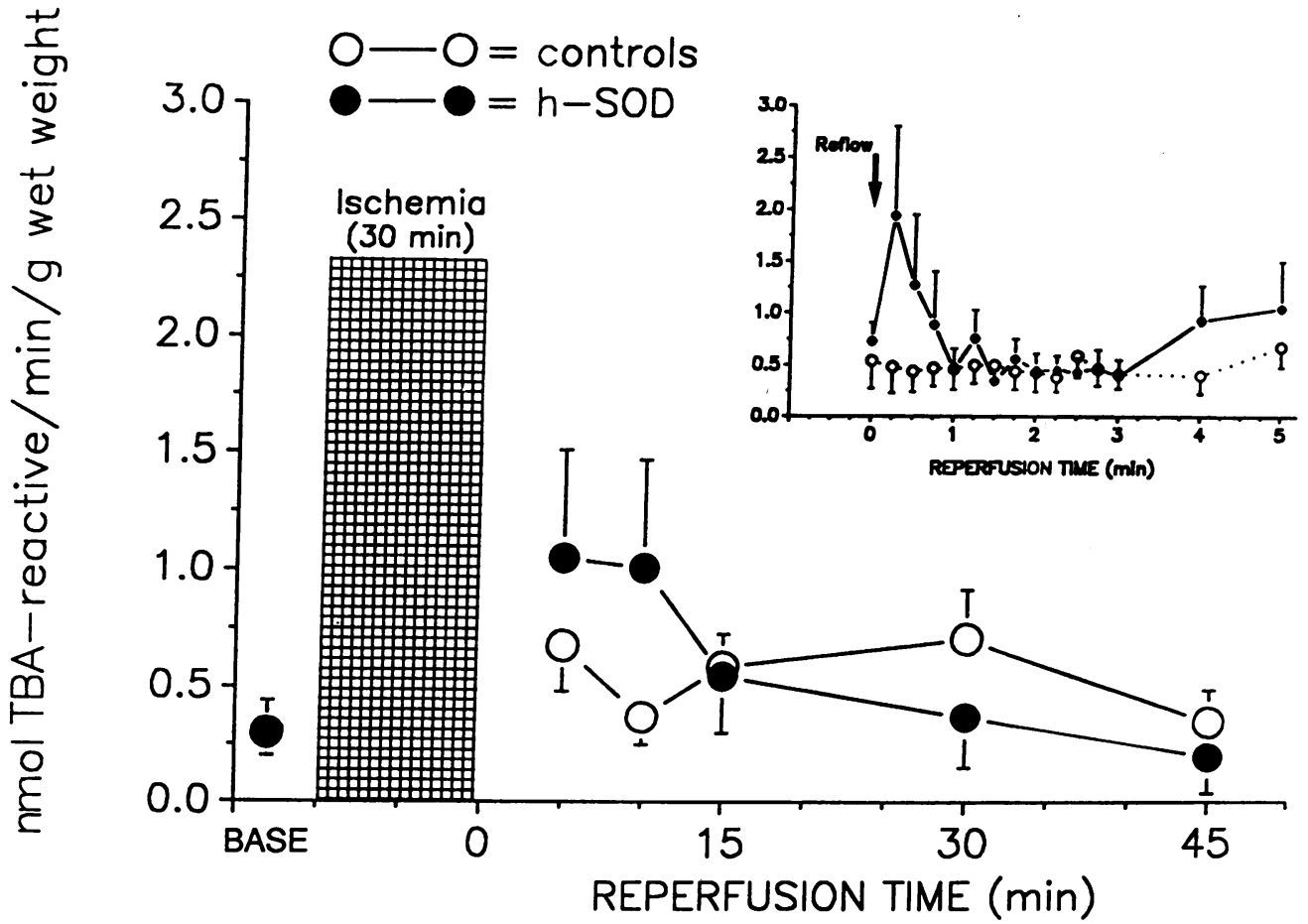

Figure 6. Time course of the release of MDA in the coronary sinus before ischemia $(B A S E)$, after reperfusion in untreated hearts, and in hearts treated at reflow with h-SOD. Results are expressed as nanomoles of thiobarbiturate-reactive material per minute per gram of wet weight. The cross-hatched area marks the period of zero-flow ischemia. The time course of MDA release during the initial $5 \mathrm{~min}$ of reflow is shown on a more detailed time scale in the inset. 


\begin{tabular}{|c|c|c|c|c|}
\hline & \multirow[b]{2}{*}{ Baseline } & \multicolumn{3}{|c|}{ Reperfusion } \\
\hline & & 15 & 30 & 45 \\
\hline & & & $\min$ & \\
\hline \multicolumn{5}{|c|}{$\begin{array}{l}\text { Left ventricular developed } \\
\text { pressure (\% baseline) }\end{array}$} \\
\hline Untreated & 100 & $46.6 \pm 5.8$ & $48.3 \pm 6.2$ & $47.7 \pm 6.8$ \\
\hline h-SOD & 100 & $52.4 \pm 4.7$ & $59.9 \pm 3.4$ & $60.6 \pm 3.1^{*}$ \\
\hline \multicolumn{5}{|c|}{ End-diastolic Pressure (mmHg) } \\
\hline Untreated & $9.4 \pm 0.3$ & $38.0 \pm 8.2$ & $33.1 \pm 7.8$ & $33.3 \pm 7.8$ \\
\hline h-SOD & $11.0 \pm 0.3$ & $23.0 \pm 3.0$ & $19.8 \pm 2.3^{*}$ & $18.9 \pm 2.4^{*}$ \\
\hline \multicolumn{5}{|c|}{ Coronary flow (\% baseline) } \\
\hline Untreated & 100 & $58.9 \pm 4.8$ & $52.7 \pm 4.7$ & $44.3 \pm 4.6$ \\
\hline h-SOD & 100 & $61.3 \pm 7.5$ & $55.1 \pm 6.3$ & $49.1 \pm 5.4$ \\
\hline
\end{tabular}

${ }^{*} P<0.05$ vs. untreated reperfused hearts.

tions. One of the first steps in this sequence is rearrangement of double bonds within the lipid molecule, into a configuration typical of a conjugated diene. The reaction will then proceed along one or both of two pathways, resulting in formation of lipid endoperoxides and/or lipid hydroperoxides (Fig. 7). Further breakdown of lipid endoperoxides results in formation of a relatively stable end product, namely MDA (12).

Chemical measurements of tissue concentrations of MDA have certain limitations. Nevertheless, MDA has been utilized widely as a marker of lipid peroxidation both in vivo and in intact hearts $(21,22,34,35,48,49,51)$. Artifactual increases in MDA content may be due to chemical interference from other TBA-reactive substances present in the sample, or to subsequent auto-oxidation causing degradation of lipid peroxides. These problems can only be partly overcome by proper assay procedures. Measurement of MDA content may also underestimate the actual degree of lipid peroxidation, since MDA is formed only when lipids containing three or more double bonds are oxidized (12). For these reasons in the present study we measured other lipid peroxidation products in addition to MDA. The observed increase in conjugated dienes content of the mitochondrial-lysosomal fraction provided additional evidence that oxygen radicals induced myocardial lipid peroxidation.

In principle, stimulation of arachidonic acid metabolism could also result in increased formation of lipid peroxides (12, 26). However, if this were the case then increased levels of lipid peroxidation products would be expected to be found in the cytosolic fraction and/or in the coronary venous effluent (i.e., near the site of prostaglandin generation). Furthermore, prostanoid synthesis might actually be stimulated by SOD (52) or other free radical scavengers (53), through preservation of vascular endothelium (54), prevention of prostaglandin synthetase inactivation by oxygen radicals (55), or direct stimulation of cyclooxygenase activity via hydrogen peroxide $(55,56)$ which is formed by SOD in the process of dismutation of superoxide anions. The finding in the present study of lipid peroxidation in the mitochondrial fraction, which was inhibited by h-SOD, would argue against increased prostaglandin synthesis as a major mechanism resulting in an increase in lipid peroxidation products after reperfusion.
The finding of increased levels of lipid peroxidation products in the subcellular fraction containing mostly mitochondria might have important pathophysiological implications. In vitro, oxygen radical attack on mitochondria promotes peroxidation of membrane lipids (57) and impairs oxidative phos-

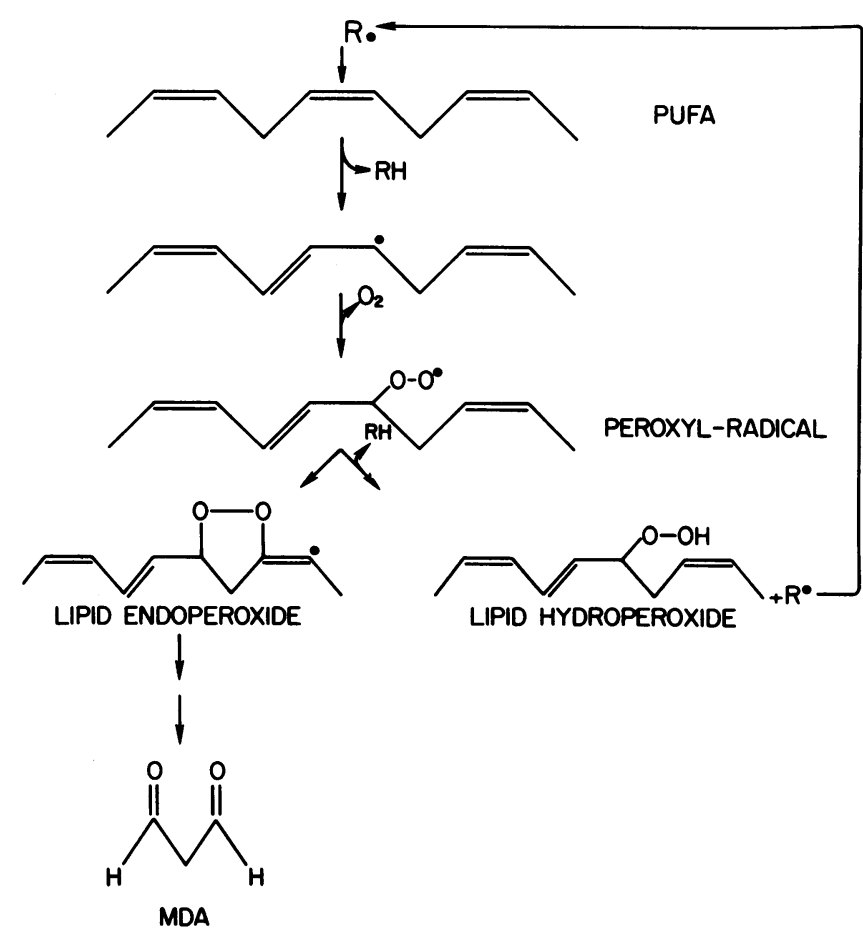

Figure 7. Schematic representation of major lipid peroxidation pathways. Reaction of a free radical $\left(R^{\circ}\right)$ with a molecule of polyunsaturated fatty acid (PUFA) results in abstraction of a hydrogen atom, with formation of a stable hydrogenated molecule $(R H)$, and of a lipid radical (marked with a dot). Note the rearrangement of the double bond attacked by the radical into a conjugated diene configuration. Subsequent oxidation will give rise to a peroxyl-radical, which may be reduced to a lipid hydroperoxide (shown on the right), or it may undergo cyclization, with formation of a lipid endoperoxide (shown on the left). The endoperoxide pathway has MDA as the end product. 
phorylation (13, 57-59). One might speculate that a peculiar membrane lipid composition of these organelles might be responsible for enhanced susceptibility to oxygen radical attack. Alternatively, detection of lipid peroxidation products might be hampered in other cellular fraction, since the yield of MDA after lipid peroxidation depends on the molecular structure of the unsaturated fatty acids attacked by free radicals $(12,60)$. In vitro experiments have documented that cardiac sarcolemmal and microsomal membranes, which differ in their lipid composition, show a different susceptibility to peroxidation by exogenously generated oxygen radicals $(15,61)$. Thus, it cannot be ruled out that lipids of the microsomal and cytosolic fraction also underwent peroxidation, and that this phenomenon was not detected because other lipid peroxidation products, different from MDA, were not measured in our study. Similarly it is also possible that plasma membranes from other cell types (e.g., endothelial cells) might be even more susceptible to lipid peroxidation than myocytes. This phenomenon may go undetected, because membranes from endothelial cells cannot be separated from the much more abundant membranes of myocytes by current techniques.

Another possible reason for enhanced mitochondrial membrane lipid peroxidation is that mitochondria might represent a preferential target for oxygen radicals formed in vivo or in intact organs. Paller et al. (48) measured the effects of SOD on the tissue content of MDA in kidneys reperfused after a period of ischemia. Similar to our findings, a significant increase in lipid peroxidation was observed in the mitochondrial fraction, which was prevented by SOD administration. Shlafer et al. (62) have reported that oxidative phosphorylation was depressed in mitochondria isolated from rabbit hearts subjected to cardioplegic arrest and reperfusion, but was virtually normal in mitochondria isolated from hearts treated with SOD and catalase. More recently, studies in intact hearts have shown that recovery of high energy phosphate metabolism was much greater in rabbit hearts treated at the time of reflow with h-SOD $(9,29)$, or deferoxamine (50). The hypothesis that oxygen radicals generated during reperfusion may deleteriously affect mitochondrial respiration is further supported by the observation that the difference in recovery of high energy phosphate levels between untreated and h-SOD-treated hearts paralleled the time course of oxygen radical production (29).

The seemingly preferential peroxidation of the mitochondrial-lysosomal fraction in the present study needs to be compared with the very recent findings of Romaschin et al. (28). In dog hearts, these authors observed a greater than threefold increase in the conjugated diene content of mitochondrial membranes after global ischemia and reperfusion, consistent with our findings. However, a much larger increase was measured in the lipid extract from purified sarcolemmal membranes, suggesting that in reperfused hearts the preferential target for the oxidative attack of oxygen radicals might actually be the sarcolemma. Several conditions might explain the apparent discrepancy between the two studies. Procedures for selective sarcolemmal isolation would require rather extensive sample manipulation, which might be associated with the artifactual formation of lipid peroxides ex vivo, due to auto-oxidation. This phenomenon might be more pronounced when isolating membranes from reperfused hearts, as they may be more susceptible to oxidation. On the other hand, since we employed a different isolation procedure, it is possible that in our study sarcolemmal membranes distributed over more than one frac- tion, and therefore the phenomenon of increased lipid peroxidation in the sarcolemma went undetected. In this respect, the case could be made that a small fraction of highly oxidized sarcolemmal membranes might have co-sedimented with the mitochondrial-lysosomal fraction, thus accounting for the increase in lipid peroxidation products, without a detectable alteration in marker enzyme activities. However, selective isolation of mitochondria by Romaschin et al. (28) also yielded increased conjugated diene content in this fraction, similar to our finding.

In addition to the differences in the methods of isolating membrane fractions, and in the length of reperfusion (i.e., $5 \mathrm{vs}$. $45 \mathrm{~min}$ in the present study), another explanation for the differences between the two studies might be found in the choice of the experimental model. Romaschin et al subjected dog hearts to global ischemia and reperfusion. We also studied global ischemia and reperfusion. However, in dog hearts a major source of oxygen radicals is represented by the activity of endothelial xanthine oxidase (63). In contrast, hearts from rabbits (and humans) have little or no xanthine oxidase activity $(64,65)$. Consequently, it might be speculated that the increased sarcolemmal peroxidation in the study of Romaschin et al. might be the consequence of a large generation of oxygen radicals in the vascular lumen, whereas other mechanisms of oxygen radical generation should be considered for the increased lipid peroxidation observed in our study. These mechanisms might act at cellular site(s) remote from the sarcolemma. In this respect, it should be pointed out that resumption of oxidative phosphorylation upon reflow (i.e., reoxygenation) might result in a large quantity of superoxide radicals being generated within the mitochondria $(57,66)$. Preliminary results from our laboratories have recently demonstrated that blockade of mitochondrial respiration reduces oxygen radical generation and mitochondrial lipid peroxidation in reperfused rabbit hearts (67).

The small but significant increase in MDA content of the microsomal fraction in hearts subjected to ischemia alone is consistent with generation of oxygen radicals during ischemia $(2,68,69)$. The different subcellular distribution of lipid peroxidation products suggests that oxygen radical generation during ischemia might occur at a different site, and/or by a different mechanism than that operating during reperfusion. This speculation is supported by the observation that administration of deferoxamine (which prevents the iron-catalyzed formation of hydroxyl radicals) can reduce the concentration of oxygen radicals in reperfused hearts $(50,69)$, but it is ineffective against oxygen radicals formed during ischemia (69).

In the present study, despite major differences in MDA and conjugated diene content, no changes in lipid hydroperoxide content were observed among the various experimental groups. Several possible mechanisms could be invoked to explain this finding. First, the ratio of endoperoxide vs. hydroperoxide formation after peroxidation of unsaturated fatty acids, can vary widely (12). Under conditions of high oxygen tension this ratio may be shifted toward endoperoxide formation, with resulting increased MDA production (70). Thus, it is possible that in the present study oxygen radical attack resulted in formation of conjugate dienes and other lipid peroxidation intermediates, which subsequently entered the endoperoxide degradation pathway (with preferential formation of MDA) rather than the hydroperoxide pathway, owing to the high oxygen tension of the perfusate (Fig. 7). Alternatively, since tissue levels of lipid peroxidation products were measured $45 \mathrm{~min}$ after 
reflow, we might have missed an increase in hydroperoxide content which would have occurred earlier during reflow. Such a transient increase might have been followed by breakdown of hydroperoxides into volatile hydrocarbons and high molecular weight aldehydes, which would go undetected (12). Lipid hydroperoxides can also undergo conversion to the corresponding fatty alcohols (12), which could subsequently be degraded via $\beta$-oxidation. Thus, the reperfusion period employed in the present study might have been of sufficient duration to account for metabolism of any excess hydroperoxides formed.

In the present study we also measured release of lipid peroxidation products in the coronary effluent. After reperfusion, the rate of MDA release from untreated hearts was only modestly increased over baseline values. Furthermore, MDA concentration in the coronary effluent was unchanged, or slightly increased as effect of h-SOD administration. These findings would suggest that the small increase of MDA release into the coronary venous effluent was most likely independent of oxygen radical generation, and perhaps reflected enhanced prostanoid synthesis (52), or greater washout. These results diverge from the observations of Das et al. (71), but are consistent with the results of several other investigators $(27,60,72)$, who also found that postischemic reperfusion did not stimulate cardiac release of MDA.

In this study, prevention of lipid peroxidation was accompanied by a significant improvement in the recovery of contractile function. Membrane lipid peroxidation has been proposed as an important mechanism of cell damage. It may alter intrinsic membrane properties, due to physicochemical changes of oxidized lipids, or secondary to cross-linking and polymerization of membrane components effected by $\operatorname{MDA}(73,74)$. In vitro, it can be shown that exposure of cell organelles to oxygen radicals results in loss of function and/or of membrane integrity, which are temporally related to the development of lipid peroxidation $(14-16,57,61,75)$. Lipid peroxidation may also indirectly contribute to other deleterious effects of ischemia/reperfusion, since it enhances phospholipid susceptibility to degradation by phospholiphases $(76,77)$, and increases membrane calcium permeability (78). In addition to these in vitro data, there is now evidence to indicate that lipid peroxidation might also exert toxic effects in vivo. Treatment with the lipid peroxidation inhibitors 21-aminosteroids reduced tissue damage in two models of cerebral ischemia-reperfusion $(79,80)$. Similarly, preliminary reports suggest that these drugs can reduce infarct size in a canine model of reperfusion injury (81). These latter studies suggest that lipid peroxidation per se might induce tissue damage, independent of other consequences of oxygen radicals.

The in vitro studies, however, have shown that peroxidation of membrane lipids is a relatively slow process. Thus, this phenomenon might not account for all the deleteriuos effects of free radicals in reperfused hearts. In particular, some functional alterations which occur immediately after reflow (e.g., reperfusion arrhythmias [82]) are likely to be mediated via other effects of oxygen radicals, perhaps on enzyme proteins (83). In this respect, in vitro studies have shown that oxidation of $\mathrm{SH}$ groups by oxygen radicals can impair $\mathrm{Ca}^{++}$-ATPase activity of sarcoplasmic reticulum (84), and $\mathrm{Na}^{+}-\mathrm{K}^{+}$-ATPase of plasma membranes (85), independent of lipid peroxidation. In the present study, we administered an enzyme which scavenges oxygen radicals before their attacking cell components. Therefore, we cannot establish whether the improved functional re- covery observed in treated hearts was due to reduction of lipid peroxidation or to prevention of other toxic effects of oxygen radicals.

In conclusion, in the present study reperfusion of postischemic hearts resulted in a significant increase in tissue content of lipid peroxidation products, particularly in the mitochondriallysosomál fraction. This phenomenon was prevented by administration of h-SOD at the time of reflow, providing strong evidence that oxygen free radicals generated during reperfusion induce membrane lipid peroxidation in postischemic hearts.

\section{Acknowledgments}

We wish to acknowledge the skillful technical assistance of Ms. Annalisa Scognamiglio. We would also like to acknowledge the valuable comments of Mack C. Mitchell, M.D. (Baltimore, MD).

This study was supported by grant 88.00230 .56 from Consiglio Nazionale delle Ricerche (Progetto Finalizzato Malattie Degenerative), Italy, Specialized Center of Research in Ischemic Heart Disease grant P50HL 17655 from the National Institutes of Health, and by NATO International Research grant 0139/88.

\section{References}

1. Hess, M. L., and N. H. Manson. 1984. Molecular oxygen: friend and foe. The role of the oxygen free radical system in the calcium paradox, the oxygen paradox and ischemia/reperfusion injury. J. Mol. Cell. Cardiol. 16:969-985.

2. Zweier, J. L., J. T. Flaherty, and M. L. Weisfeldt. 1987. Direct measurement of free radical generation following reperfusion of ischemic myocardium. Proc. Natl. Acad. Sci. USA. 84:1404-1407.

3. Zweier, J. L., B. K. Rayburn, J. T. Flaherty, and M. L. Weisfeldt. 1987. Recombinant superoxide dismutase reduces oxygen free radical concentrations in reperfused myocardium. J. Clin. Invest. 80:1728-1734.

4. Kramer, J. H., C. M. Arroyo, B. F. Dickens, and W. B. Weglicki. 1987. Spin-trapping evidence that graded myocardial ischemia alters post-ischemic superoxide production. Free Radical Biol. Med. 3:153-159.

5. Bolli, R., B. S. Patel, M. O. Jeroudi, E. K. Lai, and P. B. McCay. 1988. Demonstration of free radical generation in "stunned" myocardium of intact dogs with the use of the spin trap alpha-phenyl N-tert-butyl nitrone. J. Clin. Invest. 82:476-485.

6. Shlafer, M., P. F. Kane, V. Y. Wiggins, and M. M. Kirsh. 1982. Possible role for cytotoxic oxygen metabolites in the pathogenesis of cardiac ischemic injury. Circulation. 66(Suppl. I):85-92.

7. Myers, M. L., R. Bolli, R. F. Lekich, C. J. Hartley, and R. Roberts. 1985. Enhancement of recovery of myocardial function by oxygen free radical scavengers after reversible regional ischemia. Circulation. 72:915-921.

8. Przyklenk, K., and R. A. Kloner. 1986. Superoxide dismutase plus catalase improve contractile function in the canine model of the "stunned myocardium." Circ. Res. 58:148-156.

9. Ambrosio, G., M. L. Weisfeldt, W. E. Jacobus, and J. T. Flaherty. 1987. Evidence for a reversible, oxygen radical mediated component of reperfusion damage: Reduction by recombinant human superoxide dismutase administered at the time of reflow. Circulation. 75:282-291.

10. Jolly, S. R., W. J. Kane, M. B. Bailie, G. D. Abrams, and B. R. Lucchesi. 1984. Canine myocardial reperfusion injury. Its reduction by the combined administration of superoxide dismutase and catalase. Circ. Res. 54:277-285.

11. Ambrosio, G., L. C. Becker, G. M. Hutchins, H. F. Weisman, and M. L. Weisfeldt. 1986. Reduction in experimental infarct size by recombinant human superoxide dismutase: Insights into the pathophysiology of reperfusion injury. Circulation. 74:1424-1433.

12. Slater, T. F. 1984. Free radical mechanisms in tissue injury. Biochem. J. 222:1-15.

13. Guarnieri, C., C. Muscari, C. Ceconi, F. Flamigni, and C. M. Caldarera. 1983. Effect of superoxide generation on rat heart mitochondrial pyruvate utilization. J. Mol. Cell. Cardiol. 15:859-862.

14. Tong Mak, I., H. P. Misra, and W. B. Weglicki. 1983. Temporal relationship of free radical induced lipid peroxidation and loss of latent enzyme activity in highly enriched hepatic lysosomes. J. Biol. Chem. 258:13733-13737.

15. Kramer, J. H., I. Tong Mak, and W. B. Weglicki. 1984. Differential sensitivity of canine cardiac sarcolemmal and microsomal enzymes to inhibition by free radical induced lipid peroxidation. Circ. Res. 55:120-124. 
16. Kukreja, R. C., E. Okabe, G. M. Schrier, and M. L. Hess. 1988. Oxygen radical mediated lipid peroxidation and inhibition of $\mathrm{Ca}^{++}$-ATPase activity of cardiac sarcoplasmic reticulum. Arch. Biochem. Biophys. 261:447-457.

17. Richards, V. J., C. E. Murry, R. B. Jennings, and K. A. Reimer. 1988 Therapy to reduce free radicals during early reperfusion does not limit the size of myocardial infarcts caused by $90 \mathrm{~min}$ of ischemia in dogs. Circulation. 74:14241433.

18. Nejima, J., D. R. Knight, J. T. Fallon, N. Uemura, T. Manders, D. R Canfield, M. V. Cohen, and S. F. Vatner. 1989. Superoxide dismutase reduces reperfusion arrhythmias but fails to salvage regional function or myocardium at risk in conscious dogs. Circulation. 79:143-153.

19. Roth, E., B. Torok, T. Zsoldos, and B. Matkovics. 1985. Lipid peroxidation and scavenger mechanism in experimentally induced heart infarcts. Basic Res. Cardiol. 80:530-536.

20. Torok, B., E. Roth, V. Bar, and Z. S. Pollak. 1986. Effects of antioxidant therapy in experimentally induced heart infarcts. Basic Res. Cardiol. 81:167179.

21. Herbaczynska-Cedro, K., and W. Gordon-Majszak. 1989. Evidence for increased lipid peroxidation in the non-ischemic portion of the heart with coronary occlusion. Cardiovasc. Res. 23:98-103.

22. Guarnieri, C., F. Flamigni, and C. M. Caldarera. 1980. Role of oxygen in the cellular damage induced by re-oxygenation of hypoxic heart. J. Mol. Cell. Cardiol. 12:979-808.

23. Van Der Heide, R. S., P. A. Sobotka, C. E. Ganote. 1987. Effects of the free radical scavengers DMTU and mannitol on the oxygen paradox in perfused rat hearts. J. Mol. Cell. Cardiol. 19:615-626.

24. Brasch, H., M. H. Schoenberg, M. Younes. 1989. No evidence for an increased lipid peroxidation during reoxygenation in Langendorff hearts and isolated atria of rats. J. Mol. Cell. Cardiol. 21:697-707.

25. Romaschin, A. D., I. Rebeyka, G. J. Wilson, and D. A. G. Mickle. 1987 Conjugated dienes in ischemic and reperfused myocardium: an in vivo chemical signature of oxygen free radical mediated injury. J. Mol. Cell. Cardiol. 19:289302.

26. Capdevila, J., L. J. Marnett, N. Chacos, R. A. Prough, and R. W. Estabrook. 1982. Cytochrome P-450-dependent oxygenation of arachidonic acid to hydroxyicosatetraenoic acids. Proc. Natl. Acad. Sci. USA. 79:767-770.

27. Koller, P. T., and S. R. Bergmann. 1989. Reduction of lipid peroxidation in reperfused isolated rabbit hearts by diltiazem. Circ. Res. 65:838-846.

28. Romaschin, A. D., G. J. Wilson, U. Thomas, D. A. Feitler, L. Tumiati, and D. A. G. Mickle. 1990. Subcellular distribution of peroxidized lipids in myocardial reperfusion injury. Am. J. Physiol. 259:H116-H123.

29. Ambrosio, G., J. L. Zweier, and J. T. Flaherty. 1991. The relationship between oxygen radical generation and impairment of myocardial energy metabolism following post-ischemic reperfusion. J. Mol. Cell. Cardiol. In press.

30. Slater, T. F. 1984. Overview of methods used for detecting lipid peroxidation. Methods Enzymol. 105:283-293.

31. Bird, R. P. and H. H. Draper. 1984. Comparative studies on different methods of malonyldialdehyde determination. Methods Enzymol. 105:299-305.

32. Welman, E., and T. J. Peters. 1976. Properties of lysosomes in guinea pig heart: subcellular distribution and in vitro stability. J. Mol. Cell. Cardiol. 8:443463.

33. Weglicki, B. W., K. Owens, F. F. Kennett, A. Kessner, L. Harris, R. M. Wise, and G. V. Vahouny. 1980. Preparation and properties of highly enriched cardiac sarcolemma from isolated adult myocytes. J. Biol. Chem. 255:36053609.

34. Ohkawa, H., N. Ohishi, and K. Yaki. 1979. Assay for lipid peroxides in animal tissues by thiobarbituric acid reaction. Anal. Biochem. 95:351-358.

35. Liedtke, A. J., C. Q. Mahar, K. Ytrehus, and O. D. Mjøs. 1984. Estimates of free radical production in rat and swine hearts: methods and application of measuring malonyldialdehyde levels in fresh and frozen myocardium. Basic Res. Cardiol. 79:513-518.

36. Folch, J., M. Lees, and H. S. Stanley. 1957. A simple method for the isolation and purification of total lipids from animal tissues. J. Biol. Chem. 226:497-509.

37. Watson, B. D., R. Busto, W. J. Goldberg, M. Santiso, S. Yoshida, and M. D. Ginsberg. 1984. Lipid peroxidation in vivo induced by reversible global ischemia in rat brain. J. Neurochem. 1:268-274.

38. Aust, S. D. 1985. Lipid Peroxidation. In CRC Handbook of Methods for Oxygen Radical Research. R. A. Greenwald, editor. CRC Press Inc., Boca Raton, FL 203-207.

39. Wharton, D. C., and A. Tzagoloff 1967. Cytochrome oxidase from beef heart mitochondria. Methods Enzymol. 10:245-250.

40. Ruth, R. C., and W. B. Weglicki. 1978. The temperature-dependence of the loss of latency of lysosomal enzymes. Biochem. J. 172:163-173.

41. Scottocasa, G. L., B. Kylenstierna, L. Ernster, and A. Bergstrand. 1976. An electron-transport system associated with the outer membrane of liver mitochondria. J. Cell Biol. 32:415-438.

42. Lowry, O. H., H. J. Rosebrough, A. L. Farr, and R. J. Randall. 1951 Protein measurement with the Folin-phenol reagent. J. Biol. Chem. 193:265275.
43. Buege, J. A., and S. D. Aust. 1978. Microsomal lipid peroxidation. Methods Enzymol. 52:302-310.

44. Zweier, J. L., P. Kuppusamy, R. Williams, B. K. Rayburn, D. Smith, M. L. Weisfeldt, and J. T. Flaherty. 1989. Measurement and characterization of post ischemic free radical generation in the isolated perfused heart. J. Biol. Chem. 264:18890-18895.

45. Ambrosio, G., M. L. Weisfeldt, and J. T. Flaherty. 1988. Influence of severity of ischemia on the magnitude of myocardial reperfusion injury. J. Am Coll. Cardiol. 11:191A. (Abstr.)

46. Gross, G. J., N. E. Farber, H. F. Hardman, and D. C. Warltier. 1986. Beneficial actions of superoxide dismutase and catalase in stunned myocardium of dogs. Am. J. Physiol. 250:H372-H377.

47. Bolli, R., M. O. Jeroudi, B. S. Patel, O. I. Aruoma, B. Halliwell, E. K. Lai, and P. B. McCay. 1989. Marked reduction of free radical generation and contractile dysfunction by antioxidant therapy begun at the time of reperfusion: evidence that myocardial "stunning" is a manifestation of reperfusion injury. Circ. Res. 65:607-622.

48. Paller, M. S., J. R. Hoidal, and T. F. Ferris. 1984. Oxygen free radicals in ischemic acute renal failure in the rat. J. Clin. Invest. 74:1156-1164.

49. Zerg, R. A. 1988. Hypoperfusion-induced acute renal failure in the rat: an evaluation of oxidant tissue injury. Circ. Res. 62:430-435.

50. Ambrosio, G., J. L. Zweier, W. E. Jacobus, M. L. Weisfeldt, and J. T. Flaherty. 1987. Improvement of post-ischemic myocardial function and metabolism by administration of deferoxamine at the time of reflow: the role of iron in the pathogenesis of reperfusion injury. Circulation. 77:906-915.

51. Gupta, M., and P. K. Singal. 1989. Higher antioxidative capacity during a chronic stable heart hypertrophy. Circ. Res. 64:398-406.

52. Otani, H., R. M. Engelman, J. A. Rousou, R. H. Breyer, and D. K. Das. 1986. Enhanced prostaglandin synthesis due to phospholipid breakdown in ischemic-reperfused myocardium. Control of its production by a phospholipase inhibitor or free radical scavengers. J. Mol. Cell. Cardiol. 18:953-961.

53. Kuehl, F. A., Jr, J. L. Humes, R. W. Egan, E. A. Ham, G. C. Beveridge, and C. G. Van Arman. 1977. Role of prostaglandin endoperoxide $\mathbf{P G G}_{2}$ in inflammatory processes. Nature (Lond.). 265:170-173.

54. Mehta, J. L., D. L. Lawson, and W. W. Nichols. 1989. Attenuated coronary relaxation after reperfusion: effects of superoxide dismutase and $\mathrm{TxA}_{2}$ inhibitor U 63557A. Am. J. Physiol. 257:H1240-H1246.

55. Marshall, P. J., R. J. Kulmacz, and W. E. M. Lands. 1987. Constraints on prostaglandin biosynthesis in tissues. J. Biol. Chem. 262:3510-3517.

56. Helmer, M. E., H. W. Cook, and W. E. M. Lands. 1979. Prostaglandin biosynthesis can be triggered by lipid peroxides. Arch. Biochem. Biophys. 193:340-345.

57. Nohl, H., B. Brenninger, and D. Hegner. 1978. Influence of mitochondrial radical formation on energy linked respiration. Eur. J. Biochem. 90:385-390.

58. Harris, E. J., R. Booth, and M. B. Cooper. 1982. The effect of superoxide generation on the ability of mitochondria to take up and retain $\mathrm{Ca}^{2+}$. FEBS (Fed. Eur. Biochem. Soc.) Lett. 146:267-272.

59. Malis, C. D., and J. V. Bonventre. 1986. Mechanism of calcium potentiation of oxygen free radical injury to renal mitochondria: a model for post-ischemic and toxic mitochondrial damage. J. Biol. Chem. 261:14201-14208.

60. Lammers, J. M. J., J. M. Hartog, C. Guarnieri, I. Vaona, P. D. Verdouw, and J. F. Koster. 1988. Lipid peroxidation in normoxic and ischaemic-reperfused hearts of fish oil and lard fat fed pigs. J. Mol. Cell. Cardiol. 20:605-615.

61. Tong Mak, I., and W. B. Weglicki. 1988. Protection by beta blocking agents against free radical-mediated sarcolemmal lipid peroxidation. Circ. Res. 63:262-266.

62. Shlafer, M., P. F. Kane, and M. M. Kirsh. 1982. Superoxide dismutase plus catalase enhances the efficacy of hypothermic cardioplegia to protect the globally ischemic, reperfused heart. J. Thorac. Cardiovasc. Surg. 83:830-839.

63. Chambers, D. E., D. A. Parks, G. Patterson, R. Roy, J. M. McCord, S. Yoshida, L. F. Parmley, and J. M. Downey. 1985. Xanthine oxidase as a source of free radical damage in myocardial ischemia. J. Mol. Cell. Cardiol. 17:145-152.

64. Grum, C. M., R. A. Ragsdale, L. H. Ketai, and M. Shlafer. 1986. Absence of xanthine oxidase or xanthine dehydrogenase in rabbit myocardium. Biochem. Biophys. Res. Commun. 141:1104-1108.

65. de Jong, J. W., P. van der Meer, A. Selma Nieukoop, T. Huizer, R. J. Stroeve, and E. Bos. 1990. Xanthine oxidoreductase activity in perfused hearts of various species, including humans. Circ. Res. 67:770-773.

66. Otani, H., H. Tanaka, T. Inoue, M. Umemoto, K. Omoto, K. Tanaka, T. Sato, T. Osako, A. Masuda, A. Nonoyama, and T. Kagawa. 1984. In vitro study on contribution of oxidative metabolism of isolated rabbit heart mitochondria to myocardial reperfusion injury. Circ. Res. 55:168-175.

67. Ambrosio, G., J. L. Zweier, C. Duilio, G. Santoro, P. P. Elia, I. Tritto, M. Chiariello, and J. T. Flaherty. 1989. Inhibition of mitochondrial respiration and lipid peroxidation in reperfused hearts. Circulation. 80:II-31. (Abstr.)

68. Arroyo, C. M., J. H. Kramer, R. H. Leiboff, G. W. Mergner, B. F. Dickens, and W. B. Weglicki. 1987. Spin trapping of oxygen and carbon-centered free radicals in ischemic canine myocardium. Free Rad. Biol. Med. 3:313-316.

69. Williams, R. E., J. L. Zweier, and J. T. Flaherty. 1991. Treatment with deferoxamine during ischemia improves functional and metabolic recovery, and 
reduces reperfusion-induced oxygen radical generation in rabbits. Circulation. 83:1006-1014.

70. Reiter, R., and R. F. Burk. 1987. Effect of oxygen tension on the generation of alkanes and malonyldialdehyde by peroxidizing rat liver microsomes. Biochem. Pharmacol. 36:925-929.

71. Das, D. K., R. M. Engelman, J. A. Rousou, R. H. Breyer, H. Otani, and S. Lemeshow. 1986. Pathophysiology of superoxide radical as potential mediator of reperfusion injury in pig heart. Basic Res. Cardiol. 81:155-166.

72. Julicher, R. H. M., L. B. M. Tijburg, L. Sterrenberg, A. Bast, J. M. Koomen, and J. Noordhoek. 1984. Decreased defence against free radicals in rat heart during normal reperfusion after hypoxic, ischemic and calcium-free perfusion. Life Sci. 35:1281-1288.

73. Hoecstein, P., and S. K. Jain. 1981. Association of lipid peroxidation and polymerization of membrane protein with erythrocyte aging. Fed. Proc. 40:183192.

74. Nielsen, H. 1981. Covalent binding of peroxidized phospholipid to protein. III. Reaction of individual phospholipids with different proteins. Lipids. 16:215-223.

75. Nohl H., and D. Heghner. 1978. Do mitochondria produce oxygen radicals in vivo? Eur. J. Biochem. 82:563-567.

76. Sevanian, A., R. A. Stein, J. F. Mead. 1981. Metabolism of epoxidized phosphatydilcholine by phospholipase $A_{2}$ and epoxide hydrolase. Lipids. 16:781792.

77. Weglicki, W. B., B. F. Dickens, and I. T. Mak. 1984. Enhanced lysosomal phospholipid degradation and lysophospholipid production due to free radicals. Biochem. Byophys. Res. Commun. 124:229-235.
78. Tsokos-Kuhn, J. O., C. V. Smith, C. A. Tate, M. L. Entman, and J. R. Mitchell. 1986. Evidence for increased membrane permeability of plasmalemmal vesicles from livers of phenobarbital-induced $\mathrm{CCl}_{4}$-intoxicated rats. $\mathrm{Mol}$. Pharmacol. 30:444-451.

79. Hall, E. D., K. E. Pazara, and J. M. Braughler. 1988. 21 -aminosteroid lipid peroxidation inhibitor U74006F protects against cerebral ischemia in gerbils. Stroke. 19:997-1002.

80. Young, W., J. C. Wojak, and V. DeCrescito. 1988. 21-aminosteroid reduces ion shifts and edema in the rat middle cerebral artery occlusion model of regional ischemia. Stroke. 19:1013-1019.

81. Soufer, R., A. J. Sinusas, S. Zoghbi, and B. L. Zaret. 1990. The limitation of myocardial reperfusion injury with the 21-aminosteroid U74006F. Circulation. 82:III-37. (Abstr.)

82. Bernier, M., D. J. Hearse, and A. S. Manning. 1986. Reperfusion-induced arrhythmias and oxygen-derived free radicals: studies with "anti-free radical" interventions and a free radical-generating system in the isolated perfused rat heart. Circ. Res. 58:331-340.

83. Halliwell, B. 1987. Oxidants and human disease: some new concepts. FASEB (Fed. Am. Soc. Exp. Biol.) J. 1:358-364.

84. Scherer, N. M., and D. W. Deamer. 1986. Oxidative stress impairs the function of the sarcoplasmic reticulum by oxidation of sulphydryl groups in the $\mathrm{Ca}^{++}$-ATPase. Arch. Biochem. Biophys. 246-2:589-601.

85. Kako, K., M. Kato, T. Matsuoka, and A. Mustapha. 1988. Depression of membrane-bound $\mathrm{Na}^{+}-\mathrm{K}^{+}$-ATPase activity induced by free radicals and by ischemia of kidney. Am. J. Physiol. 254:C330-C337. 